\title{
An emm-type specific qPCR to track bacterial load during experimental human Streptococcus pyogenes pharyngitis
}

Loraine V. Fabri ${ }^{1,2+}$, Kristy I. Azzopardi ${ }^{1 \dagger}$, Joshua Osowicki ${ }^{1,3,4^{*}}$ (D), Hannah R. Frost ${ }^{1}$, Pierre R. Smeesters ${ }^{1,2,5,6}$ and Andrew C. Steer ${ }^{1,3,4}$

\begin{abstract}
Background: Streptococcus pyogenes causes a profound global burden of morbidity and mortality across its diverse clinical spectrum. To support a new controlled human infection ('challenge') model seeking to accelerate $S$. pyogenes vaccine development, we aimed to develop an accurate and reliable molecular method for quantifying bacterial load from pharyngeal swabs collected during experimental human pharyngitis.

Methods: Combined sequential RNA + DNA extraction from throat swabs was compared to traditional separate RNA-only and DNA-only extractions. An emm-type specific qPCR was developed to detect the emm75 challenge strain. Results from the qPCR were compared to culture, using throat swab samples collected in a human challenge study.

Results: The qPCR was 100\% specific for the emm75 challenge strain when tested against a panel of S. pyogenes emm-types and other respiratory pathogens. Combined RNA + DNA extraction had similar yield to traditional separate extractions. The combined extraction method and emm75 qPCR had 98.8\% sensitivity compared to culture for throat swabs collected from challenge study participants.

Conclusions: We have developed a reliable molecular method for measuring S. pyogenes bacterial load from throat swabs collected in a controlled human infection model of S. pyogenes pharyngitis.
\end{abstract}

Trial registration: NCT03361163 on 4th December 2017.

Keywords: Pharyngitis, Human challenge study, QPCR, Nucleic acid extraction, Streptococcus pyogenes

\section{Background}

Streptococcus pyogenes is a human-only pathogen with a diverse clinical spectrum including severe syndromes responsible for more than 500,000 deaths worldwide each year $[1,2]$. Hope for a vaccine to prevent $S$. pyogenes infections and their complications predates the

\footnotetext{
*Correspondence: joshua.osowicki@rch.org.au

'Loraine V. Fabri and Kristy I. Azzopardi contributed equally to this work.

'Tropical Diseases Research Group, Murdoch Children's Research Institute, Melbourne, Victoria, Australia

${ }^{3}$ Department of Paediatrics, University of Melbourne, Melbourne, Victoria, Australia

Full list of author information is available at the end of the article
}

identification of the bacterium in the late nineteenth century, when the disease spectrum was loosely considered under the historical umbrella term of scarlet fever. While vaccination is viewed as the intervention most likely to achieve sustainable diseases control, development has been impeded by regulatory, commercial, and scientific obstacles, including critical knowledge gaps regarding host-pathogen interactions [3].

Controlled human infection ('human challenge') studies recruit carefully screened volunteers who are deliberately infected under highly controlled conditions with a well-characterised strain of an infectious agent. Human

(c) The Author(s). 2021 Open Access This article is licensed under a Creative Commons Attribution 4.0 International License, which permits use, sharing, adaptation, distribution and reproduction in any medium or format, as long as you give appropriate credit to the original author(s) and the source, provide a link to the Creative Commons licence, and indicate if changes were made. The images or other third party material in this article are included in the article's Creative Commons licence, unless indicated otherwise in a credit line to the material. If material is not included in the article's Creative Commons licence and your intended use is not permitted by statutory regulation or exceeds the permitted use, you will need to obtain permission directly from the copyright holder. To view a copy of this licence, visit http://creativecommons.org/licenses/by/4.0/. The Creative Commons Public Domain Dedication waiver (http://creativecommons.org/publicdomain/zero/1.0/) applies to the data made available in this article, unless otherwise stated in a credit line to the data. 
models contribute to vaccine development as platforms for direct evaluation of vaccine protective efficacy and for detailed studies of bacterial pathogenesis and human immunity, spotlighting potential correlates of protection [4]. A multinational collaborative group established the Controlled Human Infection for Vaccination Against Streptococcus pyogenes (CHIVAS) model of experimental human $S$. pyogenes pharyngitis in healthy adult volunteers in Melbourne, Australia. The first CHIVAS study (CHIVAS-M75, ClinicalTrials.gov number NCT03361163) sought to determine a dose of a carefully selected S. pyogenes M75 strain (GenBank CP033621) required to cause pharyngitis in at least $60 \%$ of participants following direct inoculation of the pharynx by a swab [5-7]. The M75 strain was isolated from a child with acute pharyngitis in Melbourne. It was selected for use as a challenge strain according to a rationale prioritising clinical relevance and participant safety, and was extensively characterised by whole genome sequencing, in vitro assays, and in an animal model of invasive infection $[5,8]$.

The CHIVAS model includes serial collection of throat swabs for detection and quantification of pharyngeal $S$. pyogenes colonisation following the challenge procedure. We aimed to develop a robust molecular method for quantifying colonisation by the challenge strain from serial throat swabs. To study the dynamics of infection and clearance, we developed a reliable, rapid, scalable, and highly sensitive and specific method to overcome some of the limitations of traditional culture-based methods [9]. Here, we describe the performance of a type-specific emm 75 real-time quantitative PCR (qPCR) in testing DNA extracted from throat swabs collected during experimental human S. pyogenes pharyngitis in the CHIVAS-M75 trial.

\section{Methods}

\section{Collection of throat swabs}

Two throat swabs (FLOQswabs ${ }^{(\mathrm{R})}$, Copan Italia SpA) were collected on the day before challenge, approximately every $12 \mathrm{~h}$ during an inpatient period of up to 6 days, and at outpatient follow-up visits (1 week, 1 month and 3 months after discharge). One swab was stored in $1 \mathrm{ml} \mathrm{eSwab}{ }^{\text {Tw }}$ (Copan Italia SpA) solution for culture onto horse blood agar (HBA) and the other swab was placed into $2 \mathrm{ml}$ eNat $^{\mathrm{min}}$ (Copan Italia SpA) nucleic acid preservation medium (guanidine thiocyanate-based solution) and stored at $-20^{\circ} \mathrm{C}$ for up to 6 months.

\section{Preparation of genomic DNA from different bacterial species}

To assess the specificity of the emm 75 qPCR assay to distinguish the $S$. pyogenes M75 challenge strain from other common upper respiratory tract pathogens, pellets of S. pyogenes, Streptococcus pneumoniae, Staphylococcus aureus and Haemophilus influenzae were harvested by centrifugation at 2,800 rcf from $25 \mathrm{ml}$ mid-log phase cultures, and colony-forming units (CFU) were enumerated by plating. Bacterial cultures were centrifuged and genomic DNA (gDNA) was isolated from pellets using the DNeasy Blood and Tissue kit (Qiagen) according to the manufacturer's modifications for Gram-positive bacteria. Briefly, each bacterial pellet was incubated for $45 \mathrm{~m}$ at $37^{\circ} \mathrm{C}$ with $180 \mu \mathrm{l}$ of enzymatic lysis buffer (lysozyme 20 $\mathrm{mg} / \mathrm{ml}, 20 \mathrm{mM}$ Tris- $\mathrm{HCl} \mathrm{pH}$ 8.0, 2 mM EDTA and 1.2\% $\mathrm{v} / \mathrm{v}$ Triton-X), then DNA from the lysate was purified on column as per manufacturer instructions. All DNA was eluted from purification columns in a final volume of $50 \mu$ l. Concentration of eluted DNA was adjusted to $10^{4}$ Genome Equivalents $(\mathrm{GE}) / \mu \mathrm{l}$ for all $S$. pyogenes strains (assuming one genome per CFU and S. pyogenes genome size of $1.8 \mathrm{Mb}$ ). DNA from $S$. pneumoniae (clinical isolate, serotype 5), $S$. aureus (ATCC 25923) and $H$. influenzae (ATCC 10211) was adjusted to $10^{5} \mathrm{GE} / \mu \mathrm{l}$ according to their respective genome sizes $(2 \mathrm{Mb}, 2.8 \mathrm{Mb}$ and $1.8 \mathrm{Mb}$ ) [10-12]. Control human pharyngeal DNA was extracted from a healthy adult donor, using the DNeasy ${ }^{\circ}$ Blood and Tissue kit according to the instructions for mammalian cultured cells. For qPCR sensitivity testing, gDNA was prepared from a dilution series of M75 broth culture from $10^{0}$ to $10^{7} \mathrm{CFU} / \mathrm{ml}$.

\section{Separate and combined sequential extraction of RNA and DNA}

We compared RNA-only and DNA-only extractions using separate spin columns with a protocol for combined sequential RNA and then DNA extraction from the same spin column, as described by Kerllen Martins [13]. In the combined RNA + DNA method, RNA was initially isolated using a a single RNeasy $\mathrm{Mini}^{\circ}$ kit column with RNase-free water $(\mathrm{pH} 4.5)$, then DNA was eluted off the same column with elution buffer from the DNeasy Blood and Tissue kit, pH 7.5 (Additional file 1: Method S1). RNA derived using either protocol was treated with the TURBO DNA-free kit (Invitrogen) to enzymatically digest contaminating DNA. The RNA was then assessed for purity and concentration by spectrophotometry using the NanoDrop ${ }^{\text {Tw }} 2000$ system (ThermoFisher) and the 4200 TapeStation $^{\circ}$ (Agilent) prokaryotic RNA High sensitivity ScreenTape Assay.

\section{Evaluation of extraction methods}

To examine the effect of chemical pre-lysis prior to extraction, $200 \mu \mathrm{l}$ volumes of eNat ${ }^{\mathrm{tm}}$ medium containing $S$. pyogenes M75 broth culture at three concentrations $(9 \times$ $10^{2} / 10^{4} / 10^{6} \mathrm{CFU} / \mathrm{ml}$ ) was stored at $-20^{\circ} \mathrm{C}$ for 7 days. Using the combined RNA + DNA method, extraction was 
completed with and without a pre-lysis step. An additional extraction was done without pre-lysis using a larger $600 \mu \mathrm{l}$ volume of spiked eNat ${ }^{\text {tix }}$ at a single concentration $\left(9 \times 10^{4}\right.$ $\mathrm{CFU} / \mathrm{ml})$. To compare separate and combined extractions, a dilution series of $S$. pyogenes M75 broth culture (determined by spread-plate dilution) was combined with eNat ${ }^{\mathrm{mix}}$ medium for final concentrations of $3 \times 10^{1} / 10^{2} / 10^{4 /} 10^{6}$ CFU per ml. These eNat ${ }^{\text {tw }}$ tubes were frozen at $-20^{\circ} \mathrm{C}$ for 6 weeks and extraction was performed using the RNA + DNA method without pre-lysis.

\section{Quantitative PCR}

To assess the quality of simultaneously extracted RNA and DNA, the RNA was reverse transcribed using the Protoscript II Reverse Transcriptase kit (NEB) and the resulting cDNA and extracted gDNA were tested by qPCR. Relevant primer and probe sequences are listed in Table 1. The emm75 assay (IDT ${ }^{\circ}$ ) targets a $123 \mathrm{bp}$ stretch of the emm75 hypervariable region (from 146 to $268 \mathrm{bp}$ inclusive). Reactions using FAM-fluorescent probes (emm75 and speB) were performed using the GoTaq $^{\circ}$ Probe qPCR Master Mix (Promega). GoTaq ${ }^{\circ}$ $\mathrm{SYBR}^{\circ}$ green qPCR Master Mix (Promega) was used for gyrA, lytA, gltB, hpd3 and mammalian mitochondrial rRNA. Reactions were prepared using $4 \mu \mathrm{l}$ of template DNA or cDNA in a final volume of $20 \mu \mathrm{l}$ with primers and probes at a final concentration of $250 \mathrm{nM}$. Duplicate runs were completed on an AriaMX qPCR instrument (Agilent) with the following fast 2-step conditions: initial hot start of 1 cycle at $95^{\circ} \mathrm{C}$, followed by 40 cycles of denaturation at $95^{\circ} \mathrm{C}$ for $3 \mathrm{~s}$ and combined annealing/extension at $60^{\circ} \mathrm{C}$ for $30 \mathrm{~s}$. No template control (NTC) and no reverse transcriptase (NRT) controls were included in each assay.

\section{qPCR sensitivity and limit of detection}

To assess the limit of detection (LOD) for the emm75 qPCR we prepared template using a 10-fold dilution series of $S$. pyogenes M75 gDNA $\left(10^{0}-10^{7} \mathrm{CFU} / \mathrm{ml}\right)$. Ct variation at the lowest template concentration $\left(10^{\circ}\right)$ was high so these values were excluded from calculation of the standard curve. The lowest dilution to produce consistent $\mathrm{Ct}$ values was $10^{1} \mathrm{CFU} / \mathrm{ml}$, equivalent to $40 \mathrm{GE}$ of S. pyogenes M75, considered as the LOD of the emm 75 qPCR. The emm75 assay was compared to a previously published $\mathrm{qPCR}$ targeting speB, a virulence factor in the core chromosome of $S$. pyogenes and highly conserved across different $S$. pyogenes emm-types [8].

\section{qPCR specificity}

To assess the emm-type and species specificity of the emm75 qPCR assay, 14 other S. pyogenes strains were also tested, representing each of the 11 major emm clusters (E1-6, D2, D4, AC3-5), and two single protein clades [19]. Other bacteria commonly detected in the human oropharynx were also tested. The emm75 primer and probes were blasted against the online NCBI genome database (https://blast.ncbi.nlm.nih.gov/Blast.cgi) to confirm the absence of homologous sequences, besides the emm75 allele.

\section{CHIVAS-M75 study samples}

The CHIVAS-M75 study protocol has been described in detail elsewhere [6]. The study was approved by the

Table 1 Primers and probes used in this study

\begin{tabular}{|c|c|c|c|}
\hline Target & Gene & Primer and probe sequences $\left(5^{\prime}-3^{\prime}\right)$ & Reference \\
\hline \multirow[t]{8}{*}{ Streptococcus pyogenes M75 } & emm75 & Probe: 56-FAM/TGGAAAAGT/ZEN/GAAAATGATGAGCTTCGGG/3IABkFQ & This study \\
\hline & & F:AGTTACCATATGAAGCACGATACAA & \\
\hline & & R:GTTCTTCTAATCTCGTAGTCTTACCT & \\
\hline & speB & Probe: FAM-CGGCGCAGGCGGCTTCAAC-BHQ1 & [8] \\
\hline & & F: CTAAACCCTTCAGCTCTTGGTACTG & \\
\hline & & R: TTGATGCCTACAACAGCACTTTG & \\
\hline & gyrA & F: CGACTTGTCTGAACGCCAAA & [14] \\
\hline & & R: GTCAGCAATCAAGGCCAACA & \\
\hline \multirow[t]{2}{*}{ Streptococcus pneumoniae } & lytA & F: ACGCAATCTAGCAGATGAAGCA & [15] \\
\hline & & R: TCGTGCGTTTAATTCCAGCT & \\
\hline \multirow[t]{2}{*}{ Staphylococcus aureus } & $g \mid t B$ & F: CGGGTTAGGTGAATTGATTGTTTTAT & [16] \\
\hline & & R: CGCATTTGAGCTGAAGTTG & \\
\hline \multirow[t]{2}{*}{ Haemophilus influenzae } & hpd3 & F: GGTTAAATATGCCGATGGTGTTG & [17] \\
\hline & & R: TGCATCTITACGCACGGTGTA & \\
\hline \multirow[t]{2}{*}{ Mammalian mitochondrial rRNA } & $165 \mathrm{mt} r R N A$ & F: CGACCTCGATGTTGGATCAG & [18] \\
\hline & & R: GAACTCAGATCACGTAGGACTIT & \\
\hline
\end{tabular}


Alfred Hospital Human Research Ethics Committee (500/17). Twenty healthy adult volunteers were screened for $S$. pyogenes using culture and a rapid molecular point-of-care test (Abbott ID NOW Strep A 2, formerly Alere i) in the 28 days prior and then again in the $12 \mathrm{~h}$ before direct swab application of S. pyogenes M75 (at a dose of $10^{5} \mathrm{CFU} / \mathrm{ml}$ ) to the pharynx [20].

\section{Throat swab cultures using eSwab ${ }^{\text {TM }}$}

Each eSwab ${ }^{\text {Tu }}$ collected in the CHIVAS-M75 trial $(n=$ 192) was plated onto HBA at an external contract clinical laboratory according to the manufacturer instructions (Copan) within $48 \mathrm{~h}$ of collection and incubated at $37{ }^{\circ} \mathrm{C}$ in $5 \% \mathrm{CO}_{2}$. The next day, growth of $\beta$ hemolytic colonies was visually estimated according to guidelines developed in our laboratory: 10-fold dilutions of $S$. pyogenes M75 in broth culture (range $0-10^{5} \mathrm{CFU} /$ $\mathrm{ml}$ ) were prepared and an eSwab ${ }^{\text {ma }}$ dipped into each dilution for $30 \mathrm{~s}$ then plated on HBA for single colonies following the eSwab ${ }^{\text {tw }}$ protocol. Semi-quantitative growth scores were established based on the results of this test: $0=$ no growth; 1 = light; $2=$ moderate; $3=$ heavy; $4=$ profuse (Additional file 2: Figure S1). At the external laboratory, $\beta$-hemolytic colonies were selected and confirmed as S. pyogenes by MALDI-TOF mass spectrometry (Bruker Microflex) [21]. Colonies were re-plated for purity then stored at $-80{ }^{\circ} \mathrm{C}$. Pure vials were sent to our laboratory and all were confirmed as emm 75 by gene amplification and Sanger sequencing [22].

\section{Throat swabs for molecular analyses using $\mathrm{eNat}^{\mathrm{TM}}$}

Combined RNA + DNA extraction was done from 192 $\mathrm{eNat}^{\mathrm{im}}$ swabs, with laboratory staff blinded to the clinical trajectory of the source participants in the CHIVASM75 trial. Genomic DNA was quantified by qPCR and compared to the $\mathrm{eSwab}^{\text {ts }}$ semi-quantitative growth scores. Use of the extracted RNA to study gene bacterial and host expression (e.g., by reverse transcription-qPCR) will be the object of future work and is not explored in the methodology described herein. For determination of bacterial load in the eNat ${ }^{\mathrm{m}}$ samples by emm 75 qPCR: A set of standards were generated using 10-fold dilutions of S. pyogenes M75 (ranging from $10^{1}$ to $10^{7} \mathrm{CFU} / \mathrm{ml}$ ) which was then used to spike eNat ${ }^{\mathrm{Tm}}$ vials containing oropharyngeal swabs from two healthy adult donors. Standards were frozen for 7 days, thawed to mimic handling of samples from the clinical trial, and DNA extracted using the combined RNA + DNA protocol. These standards were included on each 96-well plate to generate a seven-point standard curve, along with a negative no template control (NTC). Each reaction was performed in duplicate. Cycle thresholds $(\mathrm{Ct})$ were ascertained with Agilent AriaMX 1.7 software using $\Delta \mathrm{R}$ fluorescence and automated thresholds. Reliable emm75 detection occurred at $\mathrm{Cts} \leq 35$, considered thereafter as the limit of detection (Additional file 3: Figure S2).

\section{Data analysis}

Analyses were performed using GraphPad Prism 8 software. Efficeincy of the qPCR was calculated with Agilent AriaMX software from a formula assigning 100\% when 10 -fold serial dilutions of template cause an increase of 3.3 cycles (i.e. linear regression slope $=3.3$ ) [23]. M75 bacterial load was expressed as $\log _{10}$ emm 75 genome equivalents (GE) per $\mathrm{ml}$ of eNat ${ }^{\mathrm{Tm}}$ medium. Separate or combined column extractions were compared by paired t-tests and the non-parametric Spearman coefficient was used to consider correlation between plate growth scores and emm75 GE [8].

\section{Results}

qPCR sensitivity

The emm75 qPCR assay had superior efficiency of $99.2 \%$ based on a slope of $3.3\left(R^{2}=0.999\right)$ (Fig. 1). In comparison, the speB assay had $96.5 \%$ efficiency (slope $=3.4$, $\left.\mathrm{R}^{2}=0.999\right)$. Ct values for the $s p e B$ assay were marginally lower than the emm75 assay (mean difference $0.56 \mathrm{Ct}$, 95\% CI [0.40, 0.73]), however the assays had similar levels of sensitivity, with lower limits of detection of 40 $\mathrm{GE} / \mathrm{ml}$ when corrected for efficiency.

\section{qPCR specificity}

The $e m m 75$ qPCR was $100 \%$ specific within the detectable concentration range, producing an amplification signal for assays containing emm 75 template and no signal for assays containing non-emm $75 \mathrm{~S}$. pyogenes, $\mathrm{S}$. pneumoniae, $S$. aureus, $H$. influenzae or DNA extracted from pharyngeal swabs from a healthy adult. The speB qPCR was $100 \%$ specific, being positive for all 15 S. pyogenes templates and negative for the other bacterial species tested (all 4 species were positive in relevant species-specific assays) (Additional file 4: Table S1).

\section{Evaluation of extraction methods}

Effective extraction of DNA from Gram-positive bacteria such as $S$. pyogenes usually requires an enzymatic peptidoglycan digestion step to lyse the cell wall. The eNat ${ }^{\mathrm{m}}$ medium contains lysing agents, so that a pre-lysis incubation step or addition of supplemental lytic agents may not be required. We performed DNA extraction with and without an enzymatic pre-lysis step to assess whether this influenced DNA yield in the emm 75 qPCR. At each dilution tested, pre-lysis generated lower $\mathrm{Cts}$ than extraction without pre-lysis (mean difference $0.9458 \mathrm{Ct}, P$ value $=0.03$, 95\% CI $[0.28,1.61]$; Fig. $2 \mathrm{a}$ ) . When a higher volume of eNat ${ }^{\mathrm{mm}}$ medium was processed through the column without pre-lysis $(600 \mu \mathrm{l}$ versus $200 \mu \mathrm{l}$, both $\left.9 \times 10^{4} \mathrm{CFU} / \mathrm{ml}\right)$ the mean Ct was 26.39 


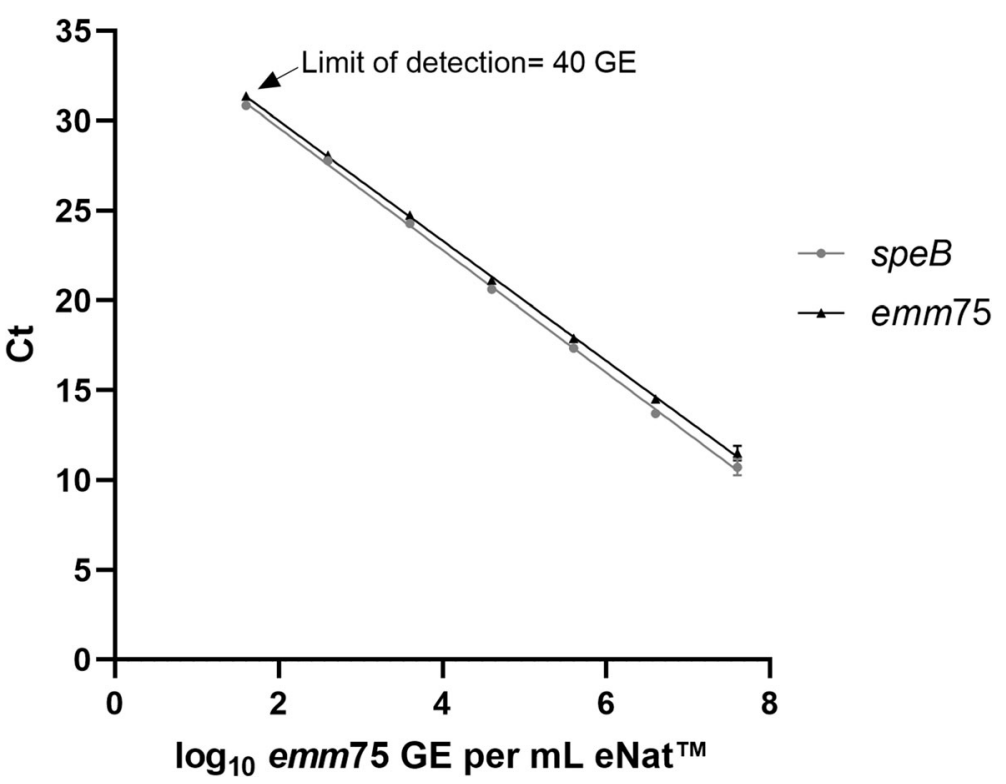

Fig. 1 Performance of the emm75 qPCR. qPCR targeting the emm75 or speB gene was performed on genomic DNA isolated from 10-fold dilutions of S. pyogenes M75. The speB qPCR was used to provide a benchmark for the performance of the emm75 qPCR, using FAM-conjugated probes for both reactions. Each point represents the mean and standard deviation (SD) of duplicate reactions

(Fig. 2a, )- lower than the extrapolated 27.27 for the equivalent bacterial load with pre-lysis ('pre-lysis' linear regression: $\mathrm{Ct}=[-2.91 \times 4.73]+41.05)$. Although not tested across a range of input bacteria CFUs, this finding suggests that increasing the processing volume of $\mathrm{eNat}^{\mathrm{m}}$ is more effective for increasing DNA yield than applying a pre-lysis step.

DNA yield from the combined RNA + DNA extraction protocol was lower than the DNA-only method as determined by UV absorbance and qPCR (mean difference $2.4 \mathrm{Ct}, P$ value $=0.03,95 \%$ CI $[0.38,4.3]$; Fig. $2 \mathrm{~b}$, Additional file 5: Table S3). As expected, for RNA (and resulting cDNA) both extraction protocols achieved similar $\mathrm{Ct}$ values and limits of detection in a $\mathrm{qPCR}$ assay targeting the S. pyogenes housekeeping gene gyrA (mean difference $0.08 \mathrm{Ct}, \mathrm{P}$ value $0.93,95 \% \mathrm{CI}$ [ -2.57 to 2.73$]$; Fig. 2b). NanoDrop ${ }^{\mathrm{Tm}}$ and TapeStation ${ }^{\circ}$ systems did not produce consistent estimations of RNA concentration

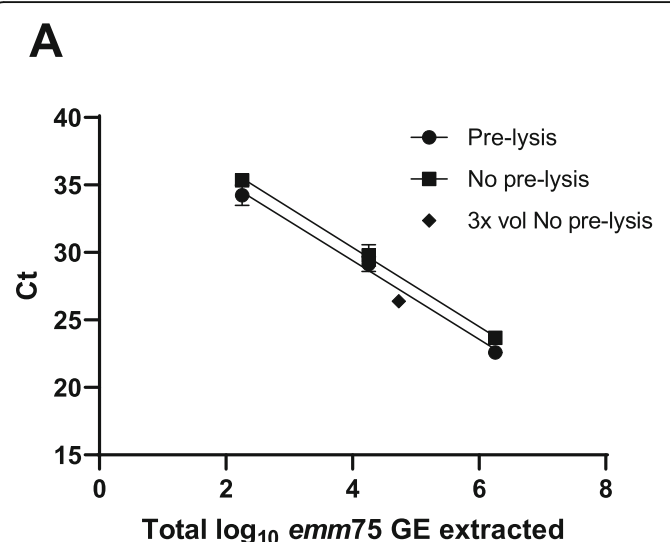

\section{B}

Fig. 2 Optimisation of the method for isolation of DNA and RNA from throat swabs in eNat ${ }^{\mathrm{TM}}$. a Pre-lysis versus No pre-lysis extractions using the combined RNA + DNA approach. eNats ${ }^{\mathrm{TM}}$ were spiked with S. pyogenes M75 at three concentrations and $200 \mu \mathrm{\mu l}$ aliquots $\left(1.8 \times 10^{2}, 1.8 \times 10^{4}, 1.8 \times\right.$

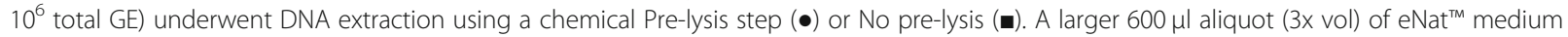
spiked with M75 (5.4 $\times 10^{4}$ total GE) was processed without pre-lysis $(\bullet)$. Data shown in total GE to account for differences in input bacteria. Each point represents the mean and SD of two eNats ${ }^{T M}$ tested in duplicate qPCRs. $\mathbf{b}$ eNats ${ }^{T M}$ containing a range of M75 were used to test separate column extractions (RNA-only $\boldsymbol{\bullet}$ or DNA-only $\bullet$ ) versus combined RNA + DNA isolation (RNA and DNAO). The emm75 qPCR was used to assess DNA whilst RNA was converted to CDNA and tested in a SYBR Green qPCR for the housekeeping gene, gyrA. Each point represents the mean and $\mathrm{SD}$ of three eNats ${ }^{\mathrm{TM}}$ tested in duplicate $\mathrm{qPCRs}$ targeting the emm75 gene 
and quality due to low concentration (Additional file 6: Table S3). As results were similar and the combined extraction protocol reduced both time and cost of extraction, this method was used for the CHIVAS-M75 study samples.

\section{Detection of emm75 bacterial load in vivo by qPCR}

During the CHIVAS-M75 study, 20 participants were challenged with $10^{5} \mathrm{CFU} / \mathrm{ml}$ of M75, and 192 paired throat swabs (between 8 and 14 time points per participant) were collected for culture $\left(\mathrm{eSwab}^{\mathrm{mix}}\right)$ and molecular testing $\left.\left(\mathrm{eNat}^{\mathrm{m}}\right)^{\mathrm{m}}\right)$. There was high correlation between culture and qPCR results (Spearman correlation $\mathrm{R}=0.8058$, $P<0.001$; Fig. 3).

Culture and qPCR results were concordant (positive or negative) for 171 of 192 evaluable sample pairs (89.1\%) (Table 2). All paired swabs taken prior to challenge were negative by both qPCR and culture. One culture-positive eSwab $^{\text {Ta }}$ was negative by qPCR, giving a sensitivity of 98.8\% (95\% CI $[97.3,100])$ for the qPCR assay. Swabs for 20 time points were qPCR positive and culture negative, including 16 collected after antibiotic treatment and 4 from the first $48 \mathrm{~h}$ after challenge in participants whose subsequent swabs were culture positive (Additional file 7: Table S4). All culture-positive swabs were verified as $S$. pyogenes M75 by qPCR and emm typing.

\section{Discussion}

We have developed a sensitive and specific quantitative PCR assay for measurement of S. pyogenes M75 from throat swabs in a human infection study of $S$. pyogenes pharyngitis. We have shown that the qPCR is specific for the emm 75 gene encoded by the challenge strain with a

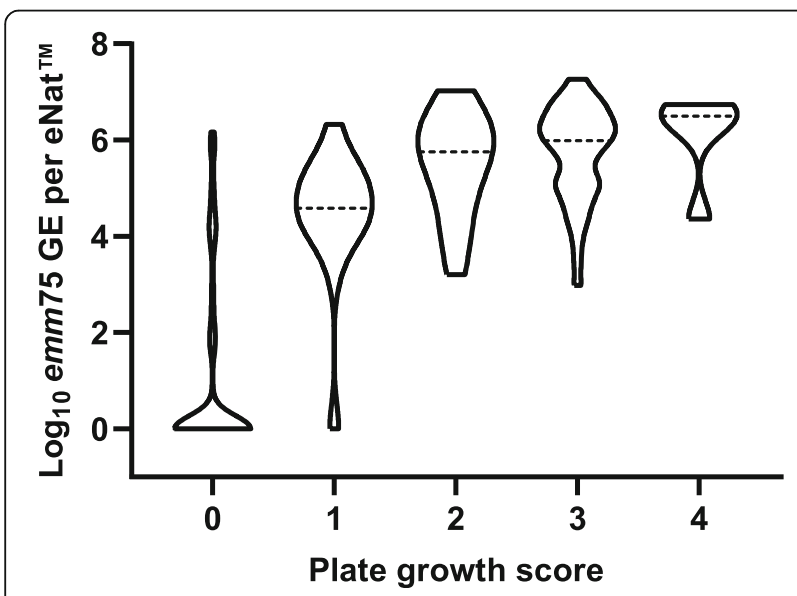

Fig. 3 Correlation between culture and $q P C R$ results. The number of emm75 genome equivalents (GE), extrapolated from qPCR Ct values, was compared to plate growth scores derived by culture. The median log10 emm75 GE of each score is represented by the dotted line (--), whilst the width of the shape reflects the density of data at the respective values
Table 2 Test results for culture and qPCR from throat swabs

\begin{tabular}{lllll}
\hline & & \multicolumn{2}{l}{ Culture } & Total PCR \\
\cline { 2 - 4 } & + & & - & \\
\hline PCR & + & 83 & 20 & $103(53.6 \%)$ \\
& - & 1 & 88 & $89(46.4 \%)$ \\
\multicolumn{2}{l}{ Total culture } & $84(43.7 \%)$ & $108(56.3 \%)$ & $192(100 \%)$ \\
\hline
\end{tabular}

A positive $\mathrm{qPCR}$ result is defined by a $\mathrm{Ct} \leq 35$ as determined by a seven-point standard curve run on each qPCR. A positive culture result is defined by a plate growth score $\geq 1$

high level of analytical performance for efficiency, specificity, and sensitivity. A lysis step prior to extraction of DNA from throat swabs stored in $\mathrm{eNat}^{\mathrm{Th}}$ was not critical for DNA extraction, attributable to bacterial lysis by the proprietary reagents in the eNat ${ }^{\mathrm{Tm}}$ medium. There were only minor differences in yield between separate RNAonly and DNA-only extractions and combined RNA + DNA isolation using a single RNeasy column. The combined approach was simpler, faster, and enabled processing of the entire $2 \mathrm{ml}$ eNat $^{\text {tix }}$ volume using a single column, reducing cost. Although not the primary aim of this study, the ability to extract quality cDNA from RNA, in addition to DNA for bacterial load quantification, increases the potential value of this technique. Finally, we compared qPCR results to semi-quantitative culture scores ('no growth' score of 0 is quantitative), showing the performance of the assay for its intended use- to measure bacterial load from throat swabs collected in a human challenge study.

Several studies have shown that qPCR is highly sensitive compared to culture and can be used to accurately quantify bacterial load during natural $S$. pyogenes pharyngitis $[8,24-27]$.

The emm75 qPCR assay we developed is rapid, scalable, and type-specific. The entire process from DNA extraction to qPCR can provide a fully quantitative result in $4 \mathrm{~h}$ and can be performed on swabs stored in eNat ${ }^{\mathrm{Th}}$ solution for at least 6 months without loss of DNA yield. The contract clinical trials facility for the CHIVAS-M75 study was offsite, with limited local laboratory capabilities, so that stability during storage and transport was critical. In comparison, the combined processes for $S$. pyogenes M75 enumeration and emm-typing by traditional methods requires at least 7 days (initial culture, purity plating, speciation, group typing, extraction of DNA, emm gene sequencing and analysis).

Historically, human infection studies for bacterial pathogens (including S. pyogenes pharyngitis studies in the 1970s) have used traditional bacterial culture methods to measure bacterial load during experimental infection [28-31]. Several non-human primate models of S. pyogenes pharyngitis have performed PCR for sample analysis (mainly for gene expression or to confirm the 
emm-type), however plate enumeration was the principal method to quantify bacterial load [32-35].

We found a strong correlation between emm 75 qPCR $\mathrm{Ct}$ values and plate growth scores. Discrepancies were noted in 20 swab pairs that were qPCR positive and culture negative, early after challenge as bacterial load was increasing or after initiation of antibiotic treatment when S. pyogenes M75 colonisation was waning. These data likely reflect the lower limit of detection and higher sensitivity of qPCR compared to culture, and detection of non-culturable bacterial elements $[8,36]$. Reduced sensitivity of bacterial culture following antibiotic treatment is common [37]. Molecular methods have also shown higher sensitivity in studies using other human pathogens, especially following antibiotic treatment $[38,39]$. There was a single pair of discordant qPCR negative and culture positive swabs, collected after antibiotic treatment. Subsequent swabs were negative by both techniques. This discrepancy is likely explained by variation in swab collection. All volunteers returned a negative qPCR result within 7 days of discharge, showing the usefulness of qPCR in differentiating persistent colonisation from relapse or re-infection during the period of outpatient follow up.

This study has several limitations. The categorical and semi-quantitative plate growth scoring system clouds direct comparison to continuous qPCR data. The $\mathrm{eSwabs}^{\mathrm{Tw}}$ for culture were collected at the off-site commercial trials facility and transferred to a contracted laboratory for culture according to diagnostic protocols and workflows with semi-quantitative enumeration as an additional step. The $\mathrm{eNat}^{\mathrm{Tm}}$ swabs were immediately frozen and later transported to our research laboratory for batched molecular testing. This variation could conceivably have contributed to differences between culture and $\mathrm{qPCR}$ results. Detection of bacterial DNA from non-viable bacteria may cause false-positive results by qPCR. For the CHIVAS-M75 trial, qPCR detection was at least equivalent to culture. Even more precise bacterial quantification could be overcome if desired in future studies using a marker of viability. As discussed, further work remains to be done with RNA extracted from throat swabs collected in the CHIVAS-M75 trial.

\section{Conclusions}

We have developed a reliable, rapid, scalable, and highly sensitive and specific molecular method to quantify pharyngeal colonisation by S. pyogenes M75 in a controlled human infection model.

\section{Abbreviations}

CDNA: Complementary DNA; CHIVAS: Controlled Human Infection for

Vaccination Against Streptococcus pyogenes; Cl: Confidence interval; Ct: Cycle thresholds; gDNA: Genomic DNA; GE: Genome equivalents; NRT: No reverse transcriptase; NTC: No template control; qPCR: Real-time quantitative polymerase chain reaction; S. pyogenes: Streptococcus pyogenes; S. pyogenes M75: Streptococcus pyogenes M75 challenge strain (ID 611024)

\section{Supplementary Information}

The online version contains supplementary material available at https://doi. org/10.1186/s12879-021-06173-w.

Additional file 1: Method S1. The protocol for combined RNA and DNA extraction from eNat ${ }^{\text {TM }}$ medium containing participant throat swabs.

Additional file 2: Figure S1. Visual guidelines for semi-quantitative scoring of the $S$. pyogenes M75 challenge strain from eSwabs ${ }^{T M}$.

Additional file 3: Figure S2. Standard curve for determination of emm75 GE in eNats ${ }^{\text {TM }}$ by qPCR. Seven-point standard curves were included on each emm75 qPCR plate and used to extrapolate bacterial load for eNat ${ }^{\text {TM }}$ throat swabs from the CHIVAS-M75 trial, expressed as emm75 genome equivalents (GE) per $\mathrm{ml}$ of eNat ${ }^{\mathrm{TM}}$ medium. The dotted line represents the limit of detection $\mathrm{Ct} \leq 35$. Mean and standard deviation shown from 7 duplicate runs.

Additional file 4: Table S1. Specificity of the emm75 qPCR. S. pyogenes from different emm-clusters and other respiratory pathogens were used to demonstrate the specificity of the emm75 QPCR. Each value is the mean of duplicate reactions. Samples with no provided Ct value failed to cross the fluorescence threshold by the 40th (last) cycle of the assay and all samples with Ct values greater than 35 were considered negative. No template control was included and this did not cross the fluorescence threshold by the 40th cycle.

Additional file 5: Table S2. Emm75 qPCR and NanoDrop DNA readings. Comparison between DNA-only and single column combined extraction methods (RNA eluted first). Refer to Fig. 2b DNA readings.

Additional file 6: Table S3. gyrA RT-qPCR and NanoDrop RNA readings. Comparison between RNA-only and single column combined extraction methods (RNA eluted first). Refer to Fig. 2b RNA readings.

Additional file 7: Table S4. Detailed timeline of discrepancies between culture and qPCR results. Twenty swabs were positive by emm75 qPCR and negative by culture. These swabs were either collected within $48 \mathrm{~h}$ after inoculation $(N=4)$ or within $36 \mathrm{~h}$ after initiation of antibiotic treatment $(N=16) .0$, pre challenge; $+24,24 \mathrm{~h}$ post challenge; Abx, antibiotics; + $1 \mathrm{w}, 1$ week post discharge; + $1 \mathrm{~m}, 1$ month post discharge; $+3 \mathrm{~m}, 3$ months post discharge.

\section{Acknowledgements}

Thank you to Dr. Jonathan Jacobson and Associate Professor Catherine Satzke for providing the S. pneumoniae, S. aureus and H. influenzae genomic DNA.

Sponsor

Murdoch Children's Research Institute.

\section{Authors' contributions}

ACS was the chief investigator for the CHIVAS-M75 study and planned this study with KIA and JO. Experimental design, experiments, statistical analysis, and preparation of the first draft of the manuscript was done by LF and KIA. HF and PS reviewed and edited manuscript drafts. All authors critically reviewed and approved the final version.

\section{Funding}

This work is supported by the Australian National Health and Medical Research Council [GNT1099183]. Loraine Fabri is supported by a grant from The Belgian Kids' Fund for Pediatric Research.

Availability of data and materials

All data generated and analysed during the study are included in this published article and its additional supplementary files. Raw datasets are available from the corresponding author on reasonable request. 


\section{Declarations}

\section{Ethics approval and consent to participate}

The CHIVAS study was approved by the Alfred Hospital Human Research Ethics Committee (500/17). Written informed consent was obtained from all participants.

\section{Consent for publication}

Not applicable.

\section{Competing interests}

The authors declare that they have no competing interests.

\section{Author details}

${ }^{1}$ Tropical Diseases Research Group, Murdoch Children's Research Institute, Melbourne, Victoria, Australia. 'Department of Paediatrics, Université Libre de Bruxelles, Brussels, Belgium. ${ }^{3}$ Department of Paediatrics, University of Melbourne, Melbourne, Victoria, Australia. ${ }^{4}$ Infectious Diseases Unit, Department of General Medicine, The Royal Children's Hospital Melbourne, Melbourne, Victoria, Australia. ${ }^{5}$ Academic Children Hospital Queen Fabiola, Université Libre de Bruxelles, Brussels, Belgium. ${ }^{6}$ Molecular Bacteriology Laboratory, Université Libre de Bruxelles, Brussels, Belgium.

Received: 2 December 2020 Accepted: 12 May 2021

Published online: 21 May 2021

\section{References}

1. Carapetis JR, Steer AC, Mulholland EK, Weber M. The global burden of group a streptococcal diseases. Lancet Infect Dis. 2005;5(11):685-94. https:// doi.org/10.1016/S1473-3099(05)70267-X.

2. Walker MJ, Barnett TC, MCArthur JD, Cole JN, Gillen CM, Henningham A, et al. Disease manifestations and pathogenic mechanisms of group a streptococcus. Clin Microbiol Rev. 2014;27(2):264-301. https://doi.org/10.112 8/CMR.00101-13.

3. Steer AC, Carapetis JR, Dale JB, Fraser JD, Good MF, Guilherme L, et al. Status of research and development of vaccines for streptococcus pyogenes. Vaccine. 2016;34(26):2953-8. https://doi.org/10.1016/j.vaccine.201 6.03.073.

4. Stanisic DI, McCarthy JS, Good MF. Controlled human malaria infection: applications, advances, and challenges. Infect Immun. 2018;86(1):e00479-17.

5. Osowicki J, Azzopardi KI, Mclntyre L, Rivera-Hernandez T, Ong CY, Baker C, et al. A controlled human infection model of group A streptococcus pharyngitis: which strain and why? mSphere. 2019;4(1):e00647-18.

6. Osowicki J, Azzopardi Kl, Baker C, Waddington CS, Pandey M, Schuster T, et al. Controlled human infection for vaccination against streptococcus pyogenes (CHIVAS): establishing a group a streptococcus pharyngitis human infection study. Vaccine. 2019;37(26):3485-94. https://doi.org/10.101 6/j.vaccine.2019.03.059

7. Osowicki J, Azzopardi KI, Fabri L, Frost HR, Rivera-Hernandez T, Neeland MR, et al. A controlled human infection model of Streptococcus pyogenes pharyngitis: an observational, dose-finding study (CHIVAS-M75). Lancet Microbe. 2021. https://doi.org/10.1016/S2666-5247(20)30240-8.

8. Dunne EM, Marshall JL, Baker CA, Manning J, Gonis G, Danchin MH, et al. Detection of group a streptococcal pharyngitis by quantitative PCR. BMC Infect Dis. 2013;13(1):312. https://doi.org/10.1186/1471-2334-13-312.

9. Oliver J, Malliya Wadu E, Pierse N, Moreland NJ, Williamson DA, Baker MG. Group a streptococcus pharyngitis and pharyngeal carriage: a meta-analysis. PLoS Negl Trop Dis. 2018;12(3):e0006335. https://doi.org/10.1371/journal. pntd.0006335

10. Camilli R, Bonnal RJ, Del Grosso M, lacono M, Corti G, Rizzi E, et al. Complete genome sequence of a serotype 11A, ST62 Streptococcus pneumoniae invasive isolate. BMC Microbiol. 2011;11(1):25. https://doi.org/10.1186/14 71-2180-11-25.

11. Treangen TJ, Maybank RA, Enke S, Friss MB, Diviak LF, Karaolis DK, et al. Complete genome sequence of the quality control strain Staphylococcus aureus subsp. aureus ATCC 25923. Genome Announc. 2014;2(6):e01110-4.

12. Fleischmann RD, Adams MD, White O, Clayton RA, Kirkness EF, Kerlavage AR, et al. Whole-genome random sequencing and assembly of Haemophilus influenzae Rd. Science. 1995:269(5223):496-512. https://doi.org/10.1126/ science.7542800
13. Kerllen Martins W. A useful procedure to isolate simultaneously DNA and RNA from a single tumor sample. PROTOCOL (Version 1) available at Protocol Exchange. 2009. doi: https://doi.org/10.1038/nprot.2009.163.

14. Brouwer S, Cork AJ, Ong CY, Barnett TC, West NP, Mclver KS, et al. Endopeptidase PepO regulates the SpeB cysteine protease and is essentia for the virulence of invasive M1T1 Streptococcus pyogenes. J Bacteriol. 2018;200(8):e00654-17.

15. Carvalho MGS, Tondella ML, McCaustland K, Weidlich L, McGee L, Mayer LW et al. Evaluation and improvement of real-time PCR assays targeting lytA, ply, and psaA genes for detection of pneumococcal DNA. J Clin Microbiol. 2007:45(8):2460-6. https://doi.org/10.1128/JCM.02498-06.

16. Diaz MH, Waller JL, Napoliello RA, Islam MS, Wolff BJ, Burken DJ, et al. Optimization of multiple pathogen detection using the TaqMan Array card: application for a population-based study of neonatal infection. PLoS One. 2013;8(6):e66183. https://doi.org/10.1371/journal.pone.0066183.

17. Wang X, Mair R, Hatcher C, Theodore MJ, Edmond K, Wu HM, et al. Detection of bacterial pathogens in Mongolia meningitis surveillance with a new real-time PCR assay to detect Haemophilus influenzae. Int J Med Microbiol. 2011;301(4):303-9. https://doi.org/10.1016/j.jimm.2010.11.004.

18. Hii SF, Senevirathna D, Llewellyn S, Inpankaew T, Odermatt P, Khieu V, et al. Development and evaluation of a multiplex quantitative Real-Time polymerase chain reaction for hookworm species in human stool. Am J Trop Med Hyg. 2018;99(5):1186-93. https://doi.org/10.4269/ajtmh.18-0276.

19. Sanderson-Smith M, De Oliveira DM, Guglielmini J, McMillan DJ, Vu T, Holien JK, et al. A systematic and functional classification of streptococcus pyogenes that serves as a new tool for molecular typing and vaccine development. J Infect Dis. 2014;210(8):1325-38. https://doi.org/10.1093/infdis/jiu260.

20. Berry GJ, Miller CR, Prats MM, Marquez C, Oladipo OO, Loeffelholz MJ, et al. Comparison of the Alere i Strep A Test and the BD veritor system in the detection of group A Streptococcus and the hypothetical impact of results on antibiotic utilization. J Clin Microbiol. 2018;56(3):e01310-7.

21. Wang J, Zhou N, Xu B, Hao H, Kang L, Zheng $Y$, et al. Identification and cluster analysis of streptococcus pyogenes by MALDI-TOF mass spectrometry. PLoS One. 2012;7(11):e47152. https://doi.org/10.1371/journal. pone.0047152.

22. CDC. Protocol for emm typing June 15, 2018 [Available from: https://www. cdc.gov/streplab/groupa-strep/emm-typing-protocol.html. Accessed 19 March 2020

23. Agilent T. AriaMx Real-Time PCR Software 2016 [updated February 2016 Available from: https://www.agilent.com/cs/library/usermanuals/Public/Aria Mx SoftwareManual.pdf. Accessed 6 June 2019.

24. Felsenstein S, Faddoul D, Sposto R, Batoon K, Polanco CM, Dien BJ. Molecular and clinical diagnosis of group a streptococcal pharyngitis in children. J Clin Microbiol. 2014;52(11):3884-9. https://doi.org/10.1128/JCM.01489-14.

25. Homme JH, Greenwood CS, Cronk LB, Nyre LM, Uhl JR, Weaver AL, et al. Duration of group a streptococcus PCR positivity following antibiotic treatment of pharyngitis. Diagn Microbiol Infect Dis. 2018;90(2):105-8. https://doi.org/10.1016/j.diagmicrobio.2017.10.003.

26. Kulkarni T, Aikawa C, Nozawa T, Murase K, Maruyama F, Nakagawa I. DNAbased culture-independent analysis detects the presence of group a streptococcus in throat samples from healthy adults in Japan. BMC Microbiol. 2016;16(1):237. https://doi.org/10.1186/s12866-016-0858-5.

27. Rao A, Berg B, Quezada T, Fader R, Walker K, Tang S, et al. Diagnosis and antibiotic treatment of group a streptococcal pharyngitis in children in a primary care setting: impact of point-of-care polymerase chain reaction. BMC Pediatr. 2019;19(1):24.

28. Chen WH, Cohen MB, Kirkpatrick BD, Brady RC, Galloway D, Gurwith M, et al. Single-dose live Oral cholera vaccine CVD 103-HgR protects against human experimental infection with Vibrio cholerae O1 El tor. Clin Infect Dis. 2016; 62(11):1329-35. https://doi.org/10.1093/cid/ciw145.

29. Harro C, Chakraborty S, Feller A, DeNearing B, Cage A, Ram M, et al. Refinement of a human challenge model for evaluation of enterotoxigenic Escherichia coli vaccines. Clin Vaccine Immunol. 2011;18(10):1719-27. https://doi.org/10.1128/CVI.05194-11.

30. Fox EN, Waldman RH, Wittner MK, Mauceri AA, Dorfman A. Protective study with a group a streptococcal M protein vaccine. Infectivity of human challenge volunteers. J Clin Invest. 1973;52(8):1885-92. https://doi.org/10.1172/JCl107372.

31. Polly SM, Waldman RH, High P, Wittner MK, Dorfman A. Protective studies with a group a streptococcal M protein vaccine. II. Challange of volenteers after local immunization in the upper respiratory tract. J Infect Dis. 1975; 131(3):217-24. https://doi.org/10.1093/infdis/131.3.217. 
32. Virtaneva K, Graham MR, Porcella SF, Hoe NP, Su H, Graviss EA, et al. Group a streptococcus gene expression in humans and cynomolgus macaques with acute pharyngitis. Infect Immun. 2003;71(4):2199-207. https://doi.org/1 0.1128/IAl.71.4.2199-2207.2003.

33. Rivera-Hernandez T, Carnathan DG, Jones S, Cork AJ, Davies MR, Moyle PM, et al. An experimental group a Streptococcus vaccine that reduces pharyngitis and tonsillitis in a nonhuman primate model. mBio. 2019;10(2):e00693-19.

34. Skinner JM, Caro-Aguilar IC, Payne AM, Indrawati L, Fontenot J, Heinrichs JH. Comparison of rhesus and cynomolgus macaques in a streptococcus pyogenes infection model for vaccine evaluation. Microb Pathog. 2011; 50(1):39-47. https://doi.org/10.1016/.micpath.2010.10.004.

35. Zhu L, Olsen RJ, Beres SB, Saavedra MO, Kubiak SL, Cantu CC, et al. Streptococcus pyogenes genes that promote pharyngitis in primates. JCl Insight. 2020;5(11):e137686. https://doi.org/10.1172/jci.insight.137686.

36. Slinger R, Goldfarb D, Rajakumar D, Moldovan I, Barrowman N, Tam R, et al. Rapid PCR detection of group a streptococcus from flocked throat swabs: a retrospective clinical study. Ann Clin Microbiol Antimicrob. 2011;10(1):33. https://doi.org/10.1186/1476-0711-10-33.

37. Wu HM, Cordeiro SM, Harcourt BH, Carvalho M, Azevedo J, Oliveira TQ, et al. Accuracy of real-time PCR, gram stain and culture for Streptococcus pneumoniae, Neisseria meningitidis and Haemophilus influenzae meningitis diagnosis. BMC Infect Dis. 2013;13:26.

38. Rockett RJ, Tozer SJ, Peatey C, Bialasiewicz S, Whiley DM, Nissen MD, et al. A real-time, quantitative PCR method using hydrolysis probes for the monitoring of plasmodium falciparum load in experimentally infected human volunteers. Malar J. 2011;10(1):48. https://doi.org/10.1186/1475-2875-10-48.

39. Pop M, Paulson JN, Chakraborty S, Astrovskaya I, Lindsay BR, Li S, et al. Individual-specific changes in the human gut microbiota after challenge with enterotoxigenic Escherichia coli and subsequent ciprofloxacin treatment. BMC Genomics. 2016;17(1):440. https://doi.org/10.1186/s12864-016-2777-0.

\section{Publisher's Note}

Springer Nature remains neutral with regard to jurisdictional claims in published maps and institutional affiliations.

Ready to submit your research? Choose BMC and benefit from:

- fast, convenient online submission

- thorough peer review by experienced researchers in your field

- rapid publication on acceptance

- support for research data, including large and complex data types

- gold Open Access which fosters wider collaboration and increased citations

- maximum visibility for your research: over $100 \mathrm{M}$ website views per year

At $\mathrm{BMC}$, research is always in progress.

Learn more biomedcentral.com/submissions 